\title{
Molecular characterization of Dirofilaria spp. circulating in Portugal
}

\author{
Cátia Ferreira ${ }^{1 \dagger}$, Ana Afonso $^{1 \dagger}$, Manuela Calado ${ }^{1}$, Isabel Maurício ${ }^{1}$, Ana Margarida Alho², José Meireles², \\ Luís Madeira de Carvalho ${ }^{2}$ and Silvana Belo ${ }^{1 *}$
}

\begin{abstract}
Background: Dirofilariosis is a potentially zoonotic parasitic disease, mainly transmitted by mosquito vectors in many parts of the world. Data concerning the canine Dirofilaria species currently circulating in Portugal is scarce. Thereby, a large-scale study was conducted to determine the Dirofilaria spp. present in Portugal, based on a molecular approach, and also to optimize a reliable and highly sensitive species-specific polymerase chain reaction $(\mathrm{PCR})$ assay that could be used for the simultaneous detection and differentiation of Dirofilaria immitis, Dirofilaria repens, and other concurrent filarial species in animal reservoirs.
\end{abstract}

Methods: Blood samples were collected from three districts of Portugal (Coimbra, Santarém and Setúbal) between 2011 and 2013. Samples were tested using rapid immunomigration tests (Witness ${ }^{\circledR}$ Dirofilaria), modified Knott’s technique and acid phosphatase histochemical staining. In addition, molecular analysis was performed by amplification of the internal transcribed spacer (ITS) region using two different PCR protocols, specific for molecular screening of canine filarial species.

Results: Of the 878 dogs sampled, $8.8 \%(n=77)$ were positive for D. immitis circulating antigen and 13.1\% $(n=115)$ positive for microfilariae by the modified Knott's technique. Of the 134 samples tested by acid phosphatase histochemical staining, 100 (74.6\%) were positive for D. immitis. Overall, 13.7\% $(n=120)$ were positive by PCR for D. immitis by ITS2, of which 9.3\% (67/720) were also positive by ITS1. ITS2 PCR was the most sensitive and specific method, capable of detecting mixed D. immitis and A. reconditum infections. Heterozygosity, in the form of double peaks, was detected by sequencing of both ITS regions. No D. repens was detected by any of the diagnostic methods.

Conclusions: The present study confirmed D. immitis as the dominant species of the genus Dirofilaria infecting Portuguese dogs, based on sequencing of ITS1 and ITS2 PCR fragments. Additionally, ITS2 PCR was the most adequate method for diagnosis and prevalence estimation.

Keywords: Dirofilaria, PCR, Internal transcribed spacer, Dog, Portugal

\section{Background}

Dirofilariosis is a potentially zoonotic filarial parasitic disease, present in several parts of the world, transmitted mainly by mosquito vectors. The species Dirofilaria immitis and Dirofilaria repens (Filarioidea, Onchocercidae) are widely present in the Mediterranean basin and are the causative agents of cardiopulmonary and subcutaneous dirofilariosis, respectively. Both nematodes are transmitted by mosquito species of the family Culicidae and can infect

\footnotetext{
* Correspondence: silvanabelo@ihmt.unl.pt

${ }^{\dagger}$ Equal contributors

${ }^{1}$ Global Health and Tropical Medicine, GHTM, Instituto de Higiene e Medicina

Tropical, IHMT, Universidade Nova de Lisboa, UNL, Lisboa, Portugal

Full list of author information is available at the end of the article
}

domestic and wild canids and felids, causing severe pathological effects [1]. Dirofilaria immitis is considered the most virulent filarial species in dogs, as the long-lived adult worms reside in the right ventricle and pulmonary artery, leading to pulmonary hypertension, congestive heart failure and even death $[2,3]$. Instead, $D$. repens adult forms live in subcutaneous tissue, where they cause dermatological problems, such as multifocal nodular and prurigo papularis dermatitis. Moreover, both species may also infect humans. Dirofilaria immitis pre-adult forms can cause pulmonary nodules and $D$. repens adult/pre-adult stages may induce subcutaneous and ocular lesions $[4,5]$. Other less known canine filarial parasites, such as Acanthocheilonema 
dracunculoides (tick- and fly-transmitted) and Acanthocheilonema reconditum (flea- and lice- transmitted), may also infect companion animals [6, 7]. Adult A. reconditum and $A$. dracunculoides reside in the peritoneal cavity and adipose tissue of the host, and thus seem to be less virulent for canine reservoirs. Nevertheless, A. reconditum has also been reported in humans [8].

These filarial species release circulating microfilariae (Mf) in the blood of their definitive hosts. These Mf can be diagnosed by microscopy through specific morphological identification or Mf histochemical staining $[9,10]$. Other diagnostic methods are also available, such as detection of circulating adult female antigens (currently only for $D$. immitis) and molecular approaches $[1,11,12]$. Modified Knott's and acid phosphatase histochemical staining tests of blood smears remain the most commonly used parasitological tests for Mf detection, but are labourintensive and require expertise. Thus, the prevalence of Dirofilaria spp. can be over-estimated if other filarial species are present and misidentified [13, 14]. Molecular protocols have been developed for reliable detection and differentiation of filarial species, in particular, a speciesspecific PCR assay and multiplex PCR and restriction fragment length polymorphism (RFLP) assays for simultaneous detection of different Dirofilaria spp., either in the vector or in blood [12, 14-21].

Canine dirofilariosis due to $D$. immitis is known to be endemic and widely distributed in Portugal, with prevalence ranging between 0.9 and $27.3 \%$ in mainland regions to over 30\% in Madeira Island [22-25]. Dirofilaria repens was recently detected for the first time, in a dog, presenting as mixed infection with $D$. immitis [26]. This is a worrying finding, as the occurrence of autochthonous infections in domestic animals and the numbers of notified human cases of dirofilariosis, mainly attributed to $D$. repens, have increased substantially in several European countries in recent years [5, 27, 28].

The aim of the present study was to identify the Dirofilaria species currently circulating in Portuguese dogs through an optimised reliable and highly sensitive species-specific PCR assay for the simultaneous detection and differentiation of $D$. immitis, D. repens and other concurrent filariids in animal reservoirs.

\section{Methods}

\section{Study areas and canine sampling examination}

The study areas, as well as the clinical and parasitological procedures, were as previously described [25]. Briefly, canine surveys were conducted in kennels (run by local authorities or animal protection associations) in three districts of Portugal: Coimbra (northern-Centre region), Santarém (central-Centre region) and Setúbal (southernCentre region) during three consecutive years: 2011, 2012 and 2013. Three surveys were carried out each year, in spring (March-April), summer (July-August) and autumn (October-November). Only dogs older than 6 months of age and residing in the kennels for at least 6 months were included.

\section{Direct and serological tests}

For clinical and parasitological examination, dogs were randomly sampled in each kennel. Physical examination was performed prior to blood collection. Blood was collected from the cephalic vein $(5 \mathrm{ml})$ and stored $(2.5 \mathrm{ml})$ with either anticoagulant EDTA or in a dry tube, and later processed for parasitological, serological and molecular analyses. The modified Knott's technique (KN) and the acid phosphatase histochemical staining test (AP) were used for microscopic detection and identification of Mf in blood smears. The commercial kit WITNESS $^{\circ}$ Dirofilaria (WT) (Synbiotics, San Diego, CA, USA) was employed for detection of $D$. immitis circulating antigen in serum.

\section{Molecular analysis \\ DNA isolation}

DNA was extracted from whole blood using CTAB (cetyltrimethyl ammonium bromide) method, adapted from Stothard et al. [29]. Briefly, $100 \mu$ l blood with EDTA (ethylenediamine tetraacetic acid) was incubated with $600 \mu \mathrm{l}$ CTAB buffer and $0.2 \mathrm{mg}$ proteinase $\mathrm{K}$ (Bioline, London, UK) at $56{ }^{\circ} \mathrm{C}$ for $2 \mathrm{~h}$, with agitation. DNA precipitation was done with $0.6 \mathrm{ml}$ absolute ethanol and the pellet hydrated in $50 \mu \mathrm{l}$ TE buffer $(10 \mathrm{mM}$ Tris, $1 \mathrm{mM}$ EDTA, pH 7.0). DNA samples were stored at $-20{ }^{\circ} \mathrm{C}$ until further use.

For D. immitis positive control, DNA was extracted, as above, from a small macerated section of two adult worms. For $D$. repens positive control, DNA was extracted from infected canine blood and from a worm (kindly provided, respectively, by Prof. Eva Fok, University of Veterinary Medicine, Budapest, Hungary, and by Prof. Claudio Genchi, University of Milan, Italy). Deionised water was used as a PCR negative control.

\section{DNA amplification}

The ribosomal internal transcribed spacer (ITS) region was amplified using two different PCR protocols for molecular screening of canine filarial species. The internal transcribed spacer 1 (ITS1) region was amplified using a semi-nested PCR as described by Nuchprayoon et al. [30]. Briefly, primers FL1-F and FL2-R were used in a first-round PCR to amplify the entire ITS region, and primers FL1-F and Di5.8S 660-R in a second-round PCR to amplify the ITS1 region, with expected amplification fragment sizes for $D$. immitis, D. repens and $A$. reconditum of 595, 602 and $446 \mathrm{bp}$, respectively. Amplification of the internal transcribed spacer 2 (ITS2) 
region was carried out using the primers DIDR-F1 and DIDR-R1 [21], with expected amplification product sizes of 542, 484, 578 and 584 bp for D. immitis, D. repens, $A$. reconditum and $A$. dracunculoides, respectively. All PCR reactions were performed in $25 \mu \mathrm{l}$ reaction mixtures, containing PCR buffer (Promega, Madison, WI, USA), $6 \mathrm{mM} \mathrm{MgCl} 2$ (Promega), $10 \mathrm{pmol}$ of each primer, $12 \mathrm{mM}$ dNTPs (Promega), $2.5 \mathrm{U} \mathrm{GoTaq}^{\circ}$ DNA polymerase (Promega), 10-40 ng of template DNA in deionized water. The temperature profile for both steps of the semi-nested ITS1 PCR was: $94{ }^{\circ} \mathrm{C}$ for $5 \mathrm{~min}$, followed by 35 cycles of $94{ }^{\circ} \mathrm{C}$ for $30 \mathrm{~s}, 58{ }^{\circ} \mathrm{C}$ for $30 \mathrm{~s}$ and $72{ }^{\circ} \mathrm{C}$ for $45 \mathrm{~s}$, with a final extension step at $72{ }^{\circ} \mathrm{C}$ for $10 \mathrm{~min}$. Amplification of the ITS2 region had the following temperature profile: $94{ }^{\circ} \mathrm{C}$ for $2 \mathrm{~min}$ and 32 cycles of $30 \mathrm{~s}$ at $94{ }^{\circ} \mathrm{C}, 30 \mathrm{~s}$ at $60^{\circ} \mathrm{C}$ and $30 \mathrm{~s}$ at $72{ }^{\circ} \mathrm{C}$, with a final extension step for $7 \mathrm{~min}$ at $72{ }^{\circ} \mathrm{C}$. Amplification products were separated by electrophoresis in $2 \%$ agarose gels, stained with ethidium bromide, and visualized under UV light.

PCR analytical sensitivity was tested with serial dilutions (by a factor of 10) of DNA from a female adult worm of $D$. immitis, canine blood infected with $D$. repens and from dog blood samples with positive PCR (ITS1/ITS2) for D. immitis.

\section{DNA sequencing and phylogenetic analysis}

PCR amplicons were purified using a commercial kit (Qiagen, QIAquick PCR Purification Kit, Germantown, USA) and sequenced commercially (Macrogen, Seoul, South Korea) using the PCR primers. A BLAST search was performed to confirm species identity of the sequenced amplicons. Homologous sequences available in GenBank/ EMBL/DDBJ databases were retrieved by BLAST and all sequences were aligned in BioEdit 7.2.5 [31]. Some sequences exhibited regions of double peaks, and haplotypes were inferred manually to correspond to homozygous sequences in circulation (for ITS1), or using the programme PHASE [32] with 100 iterations, 100 thinning interval and 100 'burn-in' settings (for ITS2).

Phylogenetic relationships were estimated using MEGA 7.0 [33], based on an alignment of regions with no gaps. The phylogenetic trees were inferred by the Maximum Parsimony method parameter, CNI (level $=1$ ) with initial tree by random addition (10 reps) with 1,000 bootstrap replicates and a cut-off value of $74 \%$.

\section{Statistical analysis}

Pearson's Chi-square and Fisher's exact tests were used to evaluate the differences between the proportions of species-specific infected dogs detected by each PCR protocol, among different age groups $(0.5-3$ years, $>3-6$ years, $>6$ years), gender and district as compared with parasitological and serological tests. Level of agreement was calculated using Cohen's kappa coefficient $(K)$. Statistical analysis was carried out using statistical software SPSS 15.0 for Windows 10.0; a $P<0.05$ was considered significant.

\section{Results}

Overall, 878 dogs (400 males and 478 females) were sampled from the three areas, Coimbra $(n=268)$, Santarém $(n=465)$ and Setúbal $(n=155)$. The dogs were 0.5 to 16 years old, with a median age of 4.5 years (IQR 2.5-7.0).

The analytical sensitivity of ITS1-PCR and ITS2-PCR were, respectively, 4.5 and $0.09 \mathrm{pg}$ DNA from female adult $D$. immitis, 118 and $200 \mathrm{pg}$ DNA from $D$. repensinfected dog blood, and 250 and 2.5 pg DNA from a $D$. immitis-infected dog. Statistical sensitivity (i.e. the proportion of true positives) and specificity (i.e. the proportion of true negatives) of ITS2-PCR were significantly higher (McNemar test, $P<0.05$ ) than of ITS1-PCR.

In the 720 dogs tested using both PCR targets, samples positive for ITS1-PCR were also positive for ITS2-PCR. Higher analytical sensitivity was observed for ITS2-PCR, with $12.9 \%$ of the blood samples positive for $D$. immitis (Table 1). Using ITS2-PCR it was possible to amplify, not only both species of Dirofilaria spp., but also $A$. reconditum in canine blood. Two samples that were ITS1-PCR-positive for D. immitis, were characterized by ITS2-PCR-RFLP as $A$. reconditum (accession number ENA: HG964682-HG964684) and were not included in the calculations. DNA from species (D. immitis and Acanthocheilonema spp.) was detected by ITS2-PCR in two samples.

The performance of the PCR with the highest analytical sensitivity (ITS2) was compared with serological and direct parasitological tests for all samples (Table 2). Out of the 878 samples tested, D. immitis circulating antigen was detected in $77(8.8 \%)$ by WT, whereas Mf were found in 115 (13.1\%) stained slides by KN method. Samples with inconsistent results between WT and KN $(n=$ 19 WT-positive, KN-negative) and KN-positive blood slides $(n=115)$ were submitted to AP analysis $(n=134)$. Out of the 134 stained slides, D. immitis Mf were identified in $100(74.6 \%)$ and $A$. reconditum in two (1.5\%). Dirofilaria repens was not identified in blood smears through any method.

ITS2-PCR and KN presented the highest level of agreement (Cohen's kappa coefficient), which was lower, but also statistically significant, between ITS2-PCR and WT (Table 3).

\section{Characterization of Dirofilaria spp.}

Sequences obtained from selected ITS1 and ITS2 PCR products were analysed and deposited in GenBank under accession numbers LN626257-LN626259 and LN626261 (samples 391, 623, 360 and 363, respectively; complete 
Table 1 Performance of ITS1 vs ITS2-PCR in 720 dog samples

\begin{tabular}{lllllll}
\hline & D. immitis & & A. reconditum & Mixed & $K$ & $P$ \\
\cline { 2 - 4 } & Positive (\%) & Negative (\%) & & Positive (\%) & Positive (\%) & \\
\hline ITS1 & $67(9.3)$ & $652(90.6)$ & $1(0.1)$ & $0(0)$ & 0.767 & 0.037 \\
ITS2 & $93(12.9)$ & $620(86.1)$ & $5(0.7)$ & $2(0.3)$ & \\
\hline
\end{tabular}

$K$ : level of agreement $(K=0.767, P=0.037)$ between each pair of tests (positive or negative results in both tests)

ITS region); KY014643-KY014648 (samples 483, 394, $350,361,488$, female adult worm, respectively; ITS1) and KY644132-KY644141 (samples 1, 7, 8, 29, 52, 483, 723, 732, 758, 846, respectively; ITS2). Three out of nine ITS1 sequences analysed from PCR products obtained from canine blood were found to have a string of double peaks, as did a female D. immitis worm (Fig. 1). The haplotypes for the ITS1 heterozygous sequences were inferred manually by assuming one sequence to be identical to the most common homozygous sequence (or haplotype) found in local samples, which in this case was H4 (Fig. 1). H4 was found in one sample from Japan, as well as the sequences AY621480.1 and AY621481.1, labelled as D. repens in the GenBank database (Fig. 1). The other inferred haplotype (H9) presented similarities with sequence EU087700, from India, but only from position 50 onwards in the alignment in Fig. 1. The region up to position 20 was more similar to other Portuguese and Japanese samples.

ITS2 sequences also presented several heterozygous sites, in particular after an A and $\mathrm{T}$ rich region. By comparison with sequences obtained from a BLAST search, the ITS2 sequences obtained here were most similar to $D$. immitis and quite distinct from $D$. repens sequences present in GenBank, as revealed by phylogenetic analysis (not shown). Statistical reconstruction of haplotypes by comparison with sequences present in GenBank identified 19 different haplotypes (Fig. 2). All heterozygous Portuguese samples included haplotype H18, which was present in sequences from India and Brazil (dog). Five samples had $\mathrm{H} 2$ as the other haplotype, which has no correspondence in the database, and two samples had haplotype $\mathrm{H} 4$, which was present in sequences from China (red panda) and Iran (dogs). The main difference between haplotype $\mathrm{H} 18$ and other haplotypes was a gap of two nucleotides in a $\mathrm{T}$ repeat. The other three haplotypes identified ( $\mathrm{H} 3, \mathrm{H} 5$ and $\mathrm{H} 11)$ were not found elsewhere in the database.
A BLAST analysis of the entire ITS region showed greatest similarities to $D$. immitis, with a sequence similarity that ranges from $89 \%$ to $97 \%$ with sequences available at NCBI database (JX866681.1; DQO18785.1; JX866681.1; FJ263464.1; FJ2634571; HM126606.1).

\section{Pattern of canine $D$. immitis infection related to gender and age}

Based on ITS2-PCR, the prevalence of $D$. immitis infection found in males $(63 / 400 ; 15.8 \%)$ was significantly higher $(P=0.032)$ than in females $(57 / 478 ; 11.9 \%)$. There were also significant differences $(P=0.01)$ in prevalence between age groups; the highest was found in dogs $>$ 6 years of age $(76 / 426 ; 17.8 \%)$, followed by the group with $>3-6$ years of age $(32 / 265 ; 12.1 \%)$ and the lowest in the $0.5-3$ years age group $(12 / 187 ; 6.4 \%)$. Similarly, statistically significant differences $(P=0.016)$ in prevalence were found between districts: Setúbal had the highest (29/155; 18.7\%), followed by Santarém (63/455; 13.8\%) and Coimbra $(28 / 268 ; 10.4 \%)$.

\section{Discussion}

The application of molecular analyses targeting filarial genomic DNA in blood samples proved in this work to be a highly sensitive and specific analytical tool for the diagnosis and simultaneous characterization of canine filarial infections $[19,21,34]$. In comparison with serological and parasitological methods, PCR provided more reliable data for clinical and epidemiological purposes.

In the present study, the ITS2-PCR had higher analytical sensitivity and specificity than the ITS1-PCR, particularly in samples with low microfilaremia $(<5 \mathrm{Mf}$ per $20 \mu \mathrm{l}$ of blood), for which ITS1 amplification failed or gave non-specific results. In addition, even in single or mixed infection cases, species identification of the filariae in infected dogs was also more consistent for ITS2 (Table 1).

Table 2 Prevalence of filarial infection according to the diagnostic assays performed

\begin{tabular}{lllll}
\hline & Total no. of samples & D. immitis & Acanthocheilonema spp. & Mixed \\
& & Positive (\%) & Positive (\%) & - \\
\hline Witness & 878 & $77(8.8)$ & - & - \\
Knott & 878 & $115(13.1)$ & - & - \\
Acid phosphatase & 134 & $100(74.6)$ & $2(1.5)$ & 2(0.2) \\
ITS2 & 878 & $120(13.7)$ & $5(0.6)$ & - \\
\hline
\end{tabular}


Table 3 Agreement between ITS2-PCR in relation to direct and serological methods

\begin{tabular}{|c|c|c|c|c|c|}
\hline Test & Total no. of samples & Positive (\%) & Negative (\%) & K & $P$ \\
\hline Witness & 878 & $65(84.4)$ & $739(92.3)$ & 0.593 & 0.042 \\
\hline Knott & 878 & $107(93.0)$ & $750(98.3)$ & 0.930 & $0.018^{*}$ \\
\hline Acid phosphatase & 134 & $97(97.0)$ & $14(43.8)$ & 0.513 & 0.088 \\
\hline
\end{tabular}

$K$ : level of agreement between each pair of tests (positive or negative results in both tests) ${ }^{*} P<0.05$

Although parasitological and serological methods are still the most frequently used techniques for the diagnosis of canine dirofilariosis [35], the present results showed that ITS2-PCR performs better in different aspects (sensitivity, specificity and species identification), thus contributing to improve diagnosis and to provide a more accurate estimation of the epidemiological pattern in the country. The ITS2-PCR assay detected mostly $D$. immitis single infections, but also $5(0.6 \%)$ cases of $A$. reconditum and $2(0.2 \%)$ of mixed infections $(D$. immitis + A. reconditum) (Table 2). ITS2-PCR was the most sensitive method, but with very similar analytical sensitivity to $\mathrm{KN}$, followed by WT.

Agreement was strongest and statistically significant between PCR-ITS2 and KN test, but the molecular assay has the advantage of detecting filarial DNA in co-infected animals. Agreement between ITS2-PCR and AP or WT was much weaker. Serology is still useful for epidemiological surveys, as it can be faster and easier to use, allowing results launching to dog owners in a short time. However, detection of D. immitis DNA in unapparent infections can complement serology in canine surveys.

Molecular results based on ITS2-PCR also confirmed previous findings of $D$. immitis infection in dogs related to sex, age, regional distribution and prevalence [25]. In fact, previous results based on WT, KN and AP tests have also shown a higher prevalence in male dogs, older than 6 years of age and from Setúbal, confirming the North-South prevalence increase trend, as reported previously based on a fast serological diagnostic kit [24].
Sequence analyses of ITS1 and ITS2 fragments identified a high number of samples with at least two different alleles, which differed in sequence length, as per the inferred haplotype sequences. Although at least one of the alleles detected in each ITS region had also been found in isolates from Portugal and other regions, some samples had inferred haploid sequences that were described here for the first time. It was not possible to determine if the parasites were heterozygous or if these were cases of mixed infections in the dog. However, one adult worm presented the same heterozygous profile for ITS2, and the same ITS heterozygous patterns had been observed in the PCR product from a mosquito in Portugal, Aedes detritus (s.l.) [36]. PCR on individually isolated Mf should clarify this issue. It is of note that some ITS1 sequences in the database had been erroneously labelled as D. repens, when, in fact, they correspond to $D$. immitis. Such observations raise the question over earlier publications of $D$. repens occurrence or prevalence based on this target.

Acanthocheilonema spp. are also common filarial nematodes that infect dogs in Europe and, although less virulent for animals, identification of $\mathrm{Mf}$ of this species in blood samples by microscopy is complex and misdiagnosis as $D$. immitis can often occur. The species-specific ITS2-PCR applied in this study detected a $0.8 \%$ prevalence of $A$. reconditum, which is similar to the prevalence found by Menn et al. [37].

The present study showed that $D$. immitis remains, so far, the dominant species of Dirofilaria genus in
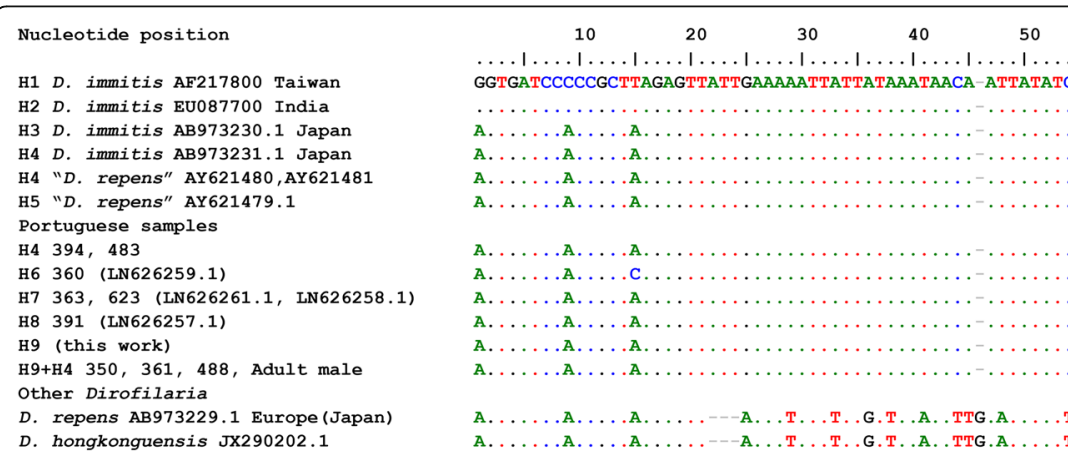
60
$\ldots 1 \ldots 1 \ldots 1 \ldots 1 \ldots$ $80 \quad 90 \quad 100$

Fig. 1 Alignment of heterozygous ITS1 sequences of D. immitis from Portuguese canine samples. The haplotypes were inferred based on circulating haplotypes, considering the most parsimonious hypothesis that at least one haplotype is the same as the most common in circulation in the population. The first position on the alignment corresponds to position 604 of the first sequence, AF217800, reversed. The nucleotide codes $K, R, S$, and $W$, correspond, respectively to $T / G, A / G, G / C$ and $A / T$ 


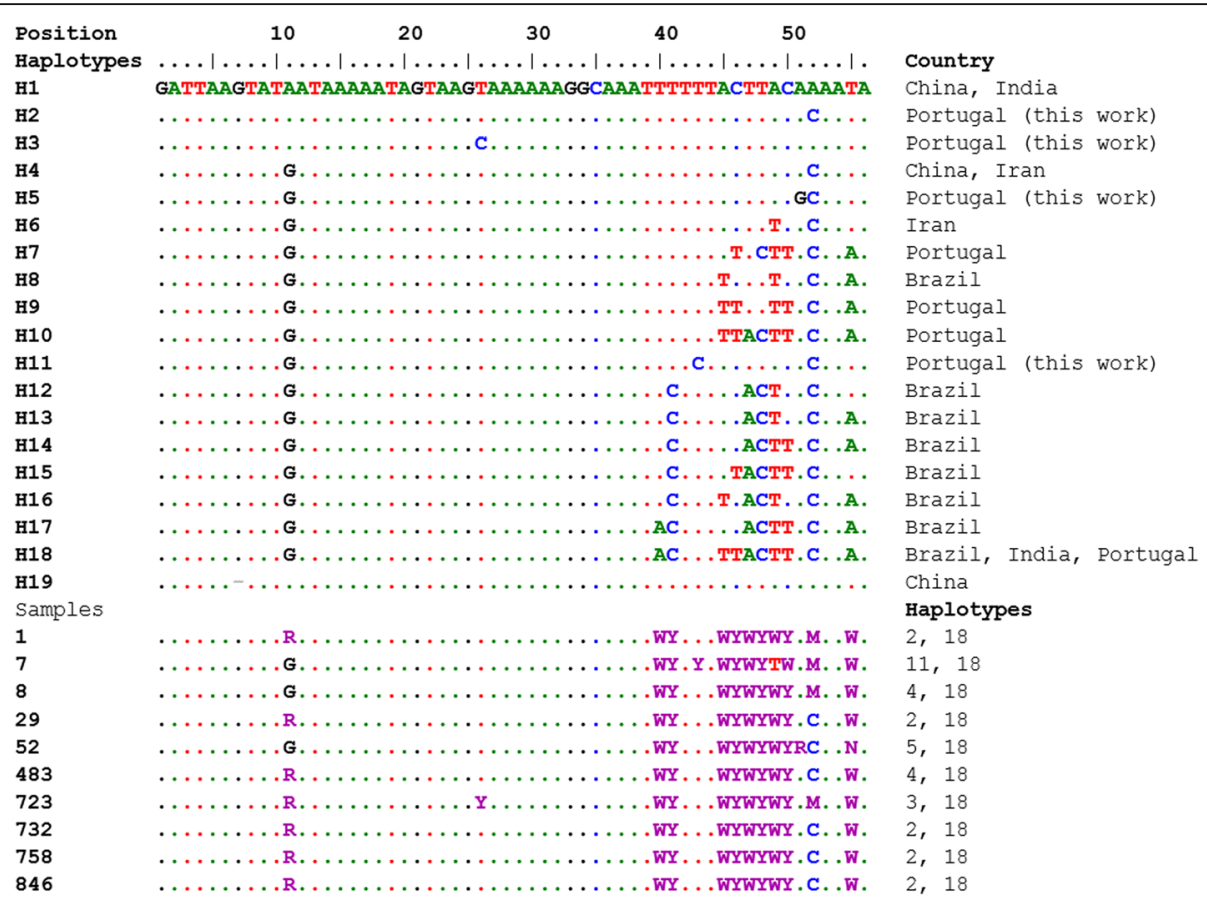

Fig. 2 Alignment of heterozygous ITS2 sequences of D. immitis from Portuguese canine samples. Haplotypes 7, 9, 10 and 18 include Portuguese sequences with codes LN626262-7 that are from infected mosquitoes. Haplotypes were inferred using the programme PHASE, by comparison with homozygous sequences, with 100 iterations, 100 thinning interval and 100 burn-in settings. The first position on the alignment corresponds to position 162 of the sequence, EU087699 (H18). The nucleotide codes are as standard ( $M, R, Y$ and $W$, correspond, respectively to $A / C, A / G, C / T$ and $\mathrm{A} / \mathrm{T}$ ). Base assignment in position 11 (R) is considered uncertain (probability of 58-9\%), as is for position 26 (Y) of sample 723 (50\%), position 43 (Y) of sample 7, and position 51 (R) of sample 52 (50\%). Haplotypes: H1: JX481279, JX866681, EU182329; H4: U182331, JN084166, JX889634, JX8896351, JX889636, JX889637, JX889638; H6: JN084168; H7: LN626265; H8: FJ263455; H9: LN626264/66; H10: LN626262; H12: FJ263458/66/67; H13: FJ263459/60/63; H14: FJ263457/64; H15: FJ263468, H16. FJ263461; H17: FJ263465; H18: EU087699, FJ263456, LN626263.1, LN626267.1; H19: EU182330. Haplotypes H2, H3, H5 and $\mathrm{H} 11$ result from inference

Portugal, as confirmed by sequencing of ITS1 and ITS2 fragments from canine blood samples. These results are consistent with the results by Ferreira et al. [36], who only detected $D$. immitis in mosquito vectors collected in the same time period in the same districts.

However, $D$. repens has recently been identified in one dog in the Algarve [26] in southern Portugal. The Algarve has the highest number of days per year with suitable conditions for Dirofilaria transmission [38] and it is, thus, likely that it has been the point of introduction of this species in Portugal. Although with very low prevalence, the presence of $D$. repens in the Algarve is worrying since this species has been implicated in the increasing number of reports of human dirofilariosis in Europe [28]. Such introduction was expected, as is the establishment and an increase in prevalence of this parasite species in Portugal, given the ongoing north- and eastward expansion of both Dirofilaria species that has been observed. Such expansion has been mainly attributed to global warming, as well as environmental changes, which promote the expansion of mosquito vectors, along with the increased international mobility of infected vertebrates [27, 39-41]. Moreover, many wild animals can also act as sylvatic reservoirs for Dirofilaria spp., thus maintaining transmission of this parasite. In Portugal, the prevalence of $D$. immitis in red foxes, as determined by necropsy, has ranged from $3.2 \%$ in northern-Centre locations, such as Coimbra [42], to $11.8 \%$ in southern and central-Centre districts, such as Santarém and Setúbal [43]. Additionally, in a national serological survey conducted in red foxes, $8.5 \%$ were positive for $D$. immitis circulating antigen, with positive animals found in northern and southern areas of Portugal [44]. Dirofilaria immitis has also been reported in three Eurasian otters, Lutra lutra, in Portuguese natural freshwater habitats $[45,46]$ and, recently, in a collection of pinnipeds from Algarve [47].

\section{Conclusions}

In conclusion, our data strongly suggest that $D$. immitis is the main etiological agent of dirofilariosis in Portugal and that PCR of the region ITS2, as applied here, could be a valuable tool for the diagnosis and screening of filarial infections in dogs, given its fast, accurate, specific detection and differentiation of Dirofilaria spp. from other concurrent blood microfilariae. 


\section{Abbreviations}

AP: Acid phosphatase histochemical staining test; CTAB: Cetyltrimethyl ammonium bromide; EDTA: Ethylenediamine tetraacetic acid; ITS: Internal transcribed spacer; KN: Modified Knott's technique; Mf: Microfilariae; PCR: Polymerase chain reaction; RFLP: Restriction fragment length polymorphism; WT: Kit WITNESS ${ }^{\oplus}$ Dirofilaria

\section{Acknowledgements}

The authors are grateful to the veterinary and auxiliary staff from municipal kennels for their collaboration; to Prof. Eva Fok (University of Veterinary Medicine, Budapest, Hungary) and Prof. Claudio Genchi (Faculty of Veterinary Medicine, University of Milan, Italy) for providing D. repens; to FCT for funds to GHTM - UID/Multi/04413/2013.

\section{Funding}

This work was sponsored by the Fundação para a Ciência e a Tecnologia (FCT), Portugal, project PTDC/SAU-SAP/113523/2009. AMA held a FCT PhD grant \# SFRH/BD/85427/2012 and was partly funded by Project UID/CVT/ 00276/2013 supported by CIISA-FMV-ULisboa, FCT, Portugal. The funders had no role in study design, data collection and analysis, decision to publish, or preparation of the manuscript. This work was done under the frame of the EurNegVec COST Action TD1303.

\section{Availability of data and materials}

All data generated or analyzed during this study are included in the article and its Additional files. Sequences obtained from selected PCR amplicons were deposited in the GenBank database under accession numbers LN626257-LN626259 and LN626261 (samples 391, 623, 360 and 363; complete ITS region); KY014643-KY014648 (samples 483, 394, 350, 361, 488, female adult worm, respectively; ITS1); and KY644132-KY644141 (samples 1 $7,8,29,52,483,723,732,758,846$, respectively; ITS2)

\section{Authors' contributions}

SB and LMC conceived and designed the research project. AMA, JM and LMC participated in the field work, conducted clinical examination and sample collection. AMA performed direct and serological analysis. CF, AA and $M C$ carried out the PCR reactions. MC and IM carried out sequence analyses and alignments. CF, AA, AMA, IM and SB wrote the paper and supervised the statistical analysis. All authors contributed, read and approved the final manuscript.

\section{Competing interests}

The authors declare that they have no competing interests.

\section{Consent for publication}

Not applicable.

\section{Ethics approval}

All the clinical procedures in this study were in accordance with Portuguese (Decree-Laws no. 314/2003 and no. 113/2013) and European legislation for the protection of animals and met the International Guiding Principles for Biomedical Research Involving Animals by the Council for the International Organizations of Medical Sciences. The protocol was approved by the Committee on Ethics of Animal and Animal Welfare (CEBEA) of the Faculdade de Medicina Veterinária, Universidade de Lisboa.

\section{Publisher's Note}

Springer Nature remains neutral with regard to jurisdictional claims in published maps and institutional affiliations.

\section{Author details}

'Global Health and Tropical Medicine, GHTM, Instituto de Higiene e Medicina Tropical, IHMT, Universidade Nova de Lisboa, UNL, Lisboa, Portugal. ${ }^{2} \mathrm{CIISA}$, Faculdade de Medicina Veterinária, Universidade de Lisboa (ULisboa), Lisboa, Portugal.
Received: 16 November 2016 Accepted: 9 May 2017

Published online: 19 May 2017

\section{References}

1. Simón F, Siles-Lucas M, Morchón R, González-Miguel J, Mellado I, Carretón E, et al. Human and animal dirofilariasis: the emergence of a zoonotic mosaic. Clin Microbiol Rev. 2012;25:507-44.

2. McCall JW, Genchi C, Kramer LH, Guerrero J, Venco L. Heartworm disease in animals and humans. Adv Parasitol. 2008;66:193-285.

3. Giangaspero A, Marangi M, Latrofa MS, Martinelli D, Traversa D, Otranto D, et al. Evidences of increasing risk of dirofilarioses in southern Italy. Parasitol Res. 2013;112:1357-61.

4. Pampiglione S, Canestri Trotti G, Rivasi F. Human dirofilariasis due to Dirofilaria (Nochtiella) repens: a review of world literature. Parassitologia. 1995;37:149-93.

5. Simón F, López-Belmonte J, Marcos-Atxutegi C, Morchón R, Martín-Pacho $J R$. What is happening outside North America regarding human dirofilariasis? Vet Parasitol. 2005:133:181-9.

6. Lindemann BA, Evans TL, McCall JW. Clinical responses of dogs to experimentally induced Dipetalonema reconditum infection. Am J Vet Res. 1983;44:2170-2

7. Rani PA, Coleman GT, Irwin PJ, Traub RJ. Hippobosca longipennis - a potential intermediate host of a species of Acanthocheilonema in dogs in northern India. Parasit Vectors. 2011:4:143.

8. Huynh T, Thean J, Maini R. Dipetalonema reconditum in the human eye. $\mathrm{Br} J$ Ophthalmol. 2001:85:1391-2.

9. Magnis J, Lorentz S, Guardone L, Grimm F, Magi M, Naucke TJ, et al. Morphometric analyses of canine blood microfilariae isolated by the Knott's test enables Dirofilaria immitis and D. repens species-specific and Acanthocheilonema (syn. Dipetalonema) genus-specific diagnosis. Parasit Vectors. 2013;6:48

10. Chalifoux L, Hunt RD. Histochemical differentiation of Dirofilaria immitis and Dipetalonema reconditum. J Am Vet Med Assoc. 1971;158:601-5.

11. Venco L, Genchi C, Simón F. La filariosis cardiopulmonar (Dirofilaria immitis) en el perro. In: Simón F, Genchi C, Venco L, Montoya MN, editors. La filariosis en las especies domésticas y en el hombre. Barcelona: Merial Laboratorios; 2011. p. 19-60.

12. Casiraghi M, Bazzocchi C, Mortarino M, Ottina E, Genchi C. A simple molecular method for discriminating common filarial nematodes of dogs (Canis familiaris). Vet Parasitol. 2006;141:368-72.

13. Scoles GA, Kambhampati S. Polymerase chain reaction-based method for the detection of canine heartworm (Filarioidea: Onchocercidae) in mosquitoes (Diptera: Culicidae) and vertebrate hosts. J Med Entomol. 1995:32:864-9.

14. Mar PH, Yang IC, Chang GN, Fei AC. Specific polymerase chain reaction for differential diagnosis of Dirofilaria immitis and Dipetalonema reconditum using primers derived from internal transcribed spacer region 2 (ITS2). Vet Parasitol. 2002;106:243-52.

15. Nuchprayoon S, Junpee A, Poovorawan Y, Scott AL. Detection and differentiation of filarial parasites by universal primers and polymerase chain reaction-restriction fragment length polymorphism analysis. Am J Trop Med Hyg. 2005;73:895-900

16. Gioia G, Lecová L, Genchi M, Ferri E, Genchi C, Mortarino M. Highly sensitive multiplex PCR for simultaneous detection and discrimination of Dirofilaria immitis and Dirofilaria repens in canine peripheral blood. Vet Parasitol. 2010;172:160-3.

17. Gasser RB, LeGoff L, Petit G, Bain O. Rapid delineation of closely-related filarial parasites using genetic markers in spacer rDNA. Acta Trop. 1996:62:143-50.

18. Watts KJ, Courteny $\mathrm{CH}$, Reddy GR. Development of a PCR- and probe-based test for the sensitive and specific detection of the dog heartworm, Dirofilaria immitis, in its mosquito intermediate host. Mol Cell Probes. 1999;13:425-30.

19. Latrofa MS, Weigl S, Dantas-Torres F, Annoscia G, Traversa D, Brianti E, et al. A multiplex PCR for the simultaneous detection of species of filarioids infesting dogs. Acta Trop. 2012;122:150-4.

20. Nuchprayoon S, Junpee A, Nithiuthai S, Chungpivat S, Suvannadabba S, Poovorawan Y. Detection of filarial parasites in domestic cats by PCR-RFLP of ITS1. Vet Parasitol. 2006:140:366-72.

21. Rishniw M, Barr SC, Simpson KW, Frongillo MF, Franz M, Dominguez Alpizar $J$ L. Discrimination between six species of canine microfilariae by a single polymerase chain reaction. Vet Parasitol. 2006;135:303-14.

22. Araujo AM. Canine and human Dirofilaria immitis infections in Portugal. A review. Parassitologia. 1996;38:366. 
23. Vieira AL, Vieira MJ, Oliveira JM, Simões AR, Diez-Baños P, Gestal J. Prevalence of canine heartworm (Dirofilaria immitis) disease in dogs of central Portugal. Parasite. 2014;21:5.

24. Cardoso L, Mendão C, Madeira de Carvalho L. Prevalence of Dirofilaria immitis, Ehrlichia canis, Borrelia burgdorferi sensu lato, Anaplasma spp. and Leishmania infantum in apparently healthy and CVBD-suspect dogs in Portugal - a national serological study. Parasit Vectors. 2012;5:62.

25. Alho AM, Landum M, Ferreira C, Meireles J, Gonçalves L, Madeira de Carvalho $L$, et al. Prevalence and seasonal variations of canine dirofilariosis in Portugal. Vet Parasitol. 2014;206:99-105.

26. Maia C, Lorentz S, Cardoso L, Otranto D, Naucke TJ. Detection of Dirofilaria repens microfilariae in a dog from Portugal. Parasitol Res. 2016;115:441-3.

27. Pampiglione S, Rivasi F, Gustinelli A. Dirofilarial human cases in the Old World, attributed to Dirofilaria immitis: a critical analysis. Histopathology. 2009:54:192-204.

28. Genchi C, Kramer LH, Rivasi F. Dirofilarial infections in Europe. Vector Borne Zoonotic Dis. 2011:11:1307-17.

29. Stothard JR, Hughes S, Rollinson D. Variation within the internal transcribed spacer (ITS) of ribosomal DNA genes of intermediate snail hosts within the genus Bulinus (Gastropoda: Planorbidae). Acta Trop. 1996;61:19-29.

30. Nuchprayoon S, Sangprakarn S, Junpee A, Nithiuthai S, Chungpivat S, Poovorawan Y. Differentiation of Brugia malayi and Brugia pahangi by PCRRFLP of ITS1 and ITS2. Southeast Asian J Trop Med Public Health. 2003;34 Suppl 2:67-73

31. Hall TA. BioEdit: a user-friendly biological sequence alignment editor and analysis program for Windows 95/98/NT. Nucl Acids Symp Ser. 1999;41:95-8.

32. Stephens M, Scheet P. Accounting for decay of linkage disequilibrium in haplotype inference and missing-data imputation. Am J Hum Genet. 2005; 76:449-62.

33. Kumar S, Stecher G, Tamura K. MEGA7: Molecular Evolutionary Genetics Analysis Version 7.0 for Bigger Datasets. Mol Biol Evol. 2016;33:1870-4.

34. Ionică AM, Matei IA, Mircean V, Dumitrache MO, D'Amico G, Győrke A, et al. Current surveys on the prevalence and distribution of Dirofilaria spp. and Acanthocheilonema reconditum infections in dogs in Romania. Parasitol Res. 2015;1 14:975-82

35. American Heartworm Society. Current canine guidelines for the prevention, diagnosis and management of heartworm (Dirofilaria immitis) infection in dogs. 2014. https://heartwormsociety.org/images/pdf/2014-AHS-CanineGuidelines.pdf. Accessed 5 Feb 2017.

36. Ferreira C, Mixão V, Novo T, Calado M, Gonçalves L, Belo S, et al. First molecular identification of mosquito vectors of Dirofilaria immitis in continental Portugal. Parasit Vectors. 2015;8:139.

37. Menn B, Lorentz S, Naucke TJ. Imported and travelling dogs as carriers of canine vector-borne pathogens in Germany. Parasit Vectors. 2010;3:34

38. Alho AM, Nunes T, Rinaldi L, Meireles J, Belo S, Deplazes $P$, et al. Transmission risk of dirofilariosis in Portugal. Parasit Vectors. 2014;7 Suppl 1:016.

39. Genchi C, Rinaldi L, Mortarino M, Genchi M, Cringoli G. Climate and Dirofilaria infection in Europe. Vet Parasitol. 2009;163:286-92.

40. Morchón R, Carretón E, Grandi G, González-Miquel J, Montoya-Alonso JA, Simón $F$, et al. Anti-Wolbachia surface protein antibodies are present in the urine of dogs naturally infected with Dirofilaria immitis with circulating microfilariae but not in dogs with occult infections. Vector Borne Zoonotic Dis. 2012;12:17-20.

41. Fuehrer HP, Auer H, Leschnik M, Silbermayr K, Duscher G, Joachim A. Dirofilaria in humans, dogs, and vectors in Austria (1978-2014) - from imported pathogens to the endemicity of Dirofilaria repens. PLoS Negl Trop Dis. 2016;10:e0004547

42. Eira C, Vingada J, Torres J, Miquel J. The helminth community of the red fox, Vulpes vulpes, in Dunas de Mira (Portugal) and its effect on host condition. Wildl Biol Pract. 2006;2:26-36.

43. Carvalho-Varela M, Marcos MVM. A helmintofauna da raposa (Vulpes vulpes silacea) em Portugal. Acta Parasitol Port. 1993;1:73-9.

44. Alho AM, Cortes H, Lopes AP, Vila-Viçosa MJ, Cardoso L, Belo S, et al. Detection of Dirofilaria immitis antigen in red foxes (Vulpes vulpes) from Portugal. Parasit Vectors. 2016;10 Suppl 1:A16.

45. Torres J, Feliu C, Fernández-Morán J, Ruíz-Olmo J, Rosoux R, Santos-Reis M, et al. Helminth parasites of the Eurasian otter Lutra lutra in southwest Europe. J Helminthol. 2004;78:353-9.

46. Saraiva AL, Sousa S, Silva J, Andrade S, Botelho N, Canavarro I, et al. Dirofilaria immitis in an Eurasian Otter (Lutra lutra). J Comp Pathol. 2013;148:88.

47. Alho AM, Marcelino I, Colella V, Flanagan C, Silva N, Correia JJ, et al. Dirofilaria immitis in pinnipeds and new host record. Parasit Vectors. 2017;10:142.

\section{Submit your next manuscript to BioMed Central and we will help you at every step:}

- We accept pre-submission inquiries

- Our selector tool helps you to find the most relevant journal

- We provide round the clock customer support

- Convenient online submission

- Thorough peer review

- Inclusion in PubMed and all major indexing services

- Maximum visibility for your research

Submit your manuscript at www.biomedcentral.com/submit
Biomed Central 